\title{
ANSELMO, CRÍTICO DE ROSCELINO ${ }^{1}$
}

\author{
Vera Rodrigues \\ Gabinete de Filosofia Medieval do \\ Instituto de Filosofia da Universidade do Porto
}

Conservada em duas recensões, compostas entre 1090 e 1093, a Epistola de incarnatione Verbi de Anselmo é um ataque, de intensidade algo surpreendente para Anselmo do Bec e de Canterbury ${ }^{2}$, das doutrinas teológicas de Roscelino de Compiègne. Se fosse ainda necessário mostrar a importância deste texto, bastaria relembrar a que ponto os nossos conhecimentos sobre Roscelino, e as suas doutrinas, estão na razão inversa da importância historiográfica que, até recentemente, lhe tem sido atribuída: a de primeiro representante do nominalismo medieval. Da sua pluma não nos resta senão uma carta, dirigida a um seu antigo discípulo, tornado então o seu mais persistente adversário: Pedro Abelardo, a cujas críticas visa precisamente responder ${ }^{3}$. Todos os outros, poucos, testemunhos que hoje nos restam das suas doutrinas filosóficas são indirectos ${ }^{4}$. De resto, a

1 Este estudo foi conduzido no âmbito de um pós-doutoramento, financiado pela Fundação para a Ciência e Tecnologia (FCT).

2 O texto anselmiano - da Epistola, como do De grammatico - é o da edição de Schmitt, F.S, Sancti Anselmi Cantuariensis Archiepiscopi, Opera Omnia, Roma/Edinburgh, 1946-1961, reproduzido em acompanhamento da tradução francesa de A. GAlONNIER, sob a direcção de M. Corbin, de L'ceuvre de S. Anselme de Cantorbery, vol. 2-3, Paris, 1986-1988. A Epistola de incarnatione Verbi será referida em nota como $D I V$ ou $D I V^{1}$, significando respectivamente a segunda e a primeira recensão.

3 A edição mais recente da Epistola ad Abaelardum é ainda a de REINERS, J., Der Nominalismus in der Frühscholastik, Münster, 1910, pp. 62-80. Recentemente, Y. Ywakuma avançou argumentos para a atribuição a Roscelino de um texto conservado num manuscrito de Munique, conhecido como Disputata Porphyrii - cf. IwAKUMA, Y., “Vocales or Early Nominalists", in Traditio 47 (1992), pp. 57-62 e 74-102.

4 Dos mais importantes, e para além da Epistola de Anselmo e de diversas passagens, bem estudadas, na obra de Abelardo, OTÃo DE FrEISING, Gesta Friderici imperatoris, I, 48, éd. G. WAITZ et B. von SIMSON, MGH Scriptores, Hannover-Leipzig, 1912 , p. 69, diz-nos que Roscelino foi o primeiro da época a introduzir em lógica o

Philosophica, 34, Lisboa, 2009, pp. 125-143 
crítica de Anselmo teve uma repercussão considerável, e não só nos meios monásticos que eram naturalmente os seus (e os de difusão privilegiada da sua obra $)^{5}$. Uma difusão que Anselmo terá pretendido, já que, justamente, a segunda recensão da Epistola - redigida já após o Concílio de Soissons de ca. 1090/92, que condenou Roscelino - é dirigida ao Papa Urbano $\mathrm{II}^{6}$. Na fórmula impressiva de Anselmo, Roscelino seria um desses novos "heréticos da dialéctica, que defendem que as substâncias universais não são mais do que emissões de voz (flatus vocis)" ". Esta sua caracterização circulou certamente de maneira eficaz entre os mestres de um ensino mais tradicionalista e mais cioso dos conteúdos da fé. Hermann de Tournai faz-lhe explicitamente referência ${ }^{8}$, mas também o seu

ensino das palavras (sententiam vocum); no mesmo sentido, a L'Historia francica, éd. M. Bouquet, Recueil des historiens des Gaules et de la France, vol.12, Paris, 1781 , p. 3, dá-nos a célebre e tão perscrutada passagem em que é mencionado um misterioso João, que defendia que a dialéctica era uma ars vocalis, e de quem Roscelino e vários outros mestres haviam seguido o ensino. Para outros elementos e indícios sobre a biografia e o meio de Roscelino, veja-se MEws, C., "The trinitarian doctrine of Roscelin of Compiègne and its influence: twelfth-century nominalism and theology re-considered", in DE LIBERA, A., ElAMrANi-JAMAL, A., GAlONNIER, A., (ed.), Mélanges offerts à Jean Jolivet, Paris, 1997, espec. pp. 348-52 e, do mesmo autor, "St. Anselm, Roscelin and the see of Beauvais", in LuscomBE, D. E. and Evans, G.R. (eds.), Anselm: Aosta, Bec and Canterbury. Proceedings in Commemoration of the Nine-Hundredeth Anniversary of Anselm's Enthronement as Archbishop, 25 September 1093, Sheffield, 1996), pp. 106-119 (ambos reimp. in ID., Reason and Belief in the Age of Roscelin and Abelard, Aldershot, 2002).

5 Sobre a influência e a difusão da obra de Anselmo, veja-se G.R. EvANS, “Anselm's life, works and immediate influence", in DAVIS, B. e LEFTOW, B. (éd.), The Cambridge Companion to Anselm, Cambridge, 2004, pp. 5-31.

${ }^{6} \mathrm{O}$ epistolário de Anselmo dá-nos informações importantes sobre a composição da Epistola: a primeira recensão, sob a forma de carta aberta, era aparentemente destinada ao Concílio de Soissons, em que Roscelino foi forçado a abjurar das suas doutrinas heréticas (Ep. 136 a Fulco de Beauvais); a segunda recensão foi composta pelo já então arcebispo de Canterbury (Março de 1093), uma vez que Roscelino continuava a propagar as suas doutrinas (Ep. 136 a Fulco de Beauvais). Anselmo só indirectamente terá tido conhecimento das doutrinas de Roscelino, que lhe terão sido transmitidas por um certo João, monge do Bec (Ep. 128). C. Mews pensa ter encontrado uma outra versão ainda (para além das três intermediárias assinaladas por Schmitt) num texto que intitula, de acordo com o seu incipit, "Cur deus magis" - cf., "St. Anselm and Roscelin: some new texts and their implications. I. The De incarnatione uerbi and the Disputatio inter christianum et gentilem", in Archives d'histoire doctrinale et littéraire du Moyen Age 58 (1991), pp. 55-98 (reimp. in ID., Reason and Belief in the Age of Roscelin and Abelard, Aldershot, 2002).

7 Cf. n.19 infra. Observe-se que esta passagem é dada apenas pela segunda recensão.

8 Hermann de Tournai, Narratio restaurationis Sancti Martini Tornacensis, ed. G. Waitz, MGH SS 14, Hannover, 1883, p. 274ff - passagem citada por MEwS, C., "St. Anselm and Roscelin of Compiègne. Some new texts and their implications. II. A vocalist essay on the Trinity and intellectual debate c. 1080-1120", in Archives d'histoire doctrinale et littéraire du Moyen Âge 65 (1998), p. 54 (reimp. in ID., 
segundo mais poderoso crítico, já mencionado, Abelardo?

Historiograficamente, o perfil teórico que descreve Anselmo desses novos "heréticos da dialéctica" contribuiu grandemente para a ideia da existência, nesta época e no Norte da França, de um grupo de mestres que negavam a existência real dos universais. Como o mostrou Y. Iwakuma, esses mestres eram então chamados de vocales (vocalistas) pelos seus críticos - tendo o termo nominales aparecido apenas em meados do século XII, para se referir em particular aos discípulos de Abelardo ${ }^{10}$. Outros dos mais recentes resultados da investigação têm vindo a pôr em evidência a importância dos debates lógico-gramaticais e semânticos da época na emergência, e configuração, da chamada "querela dos universais" e, muito particularmente, da confrontação entre as Institutiones grammaticae de Prisciano e as Categorias de Aristóteles, acompanhadas da Isagoge de Porfírio e dos comentários lógicos de Boécio ${ }^{11}$. Essa confrontação, e as dificuldades que daí resultam, são particularmente evidentes num importante comentário, anónimo e ainda inédito, às Institutiones de Prisciano - as Glosulae in Priscianum - datando do final do século XII, bem como numa série de comentários, igualmente anónimos e de intrincada transmissão manuscrita, aos principais textos da logica vetus ${ }^{12}$. Distante

Reason and Belief...), com quem reenviamos igualmente para EVANS, G.R., Anselm and a new generation, Oxford, 1980, sobre a influência de Anselmo em Hermann e, sobretudo, em Odon de Tournai, importante expoente do realismo.

9 ABElardo, Theologia 'Summi boni', II.75, ed. Buytaert, Y. e Mews, C., CCCM 13, Turnhout, 1987, p. 140; ID., Theologia christiana III.31, CCC12, Turnhout, 1969, p. 244.

10 IwaKuma, Y., "Vocales ..." e ID., "Vocales Revisited", in The Word in Medieval Logic and Grammar, XIIIth Annual Colloquium, S.I.E.P.M, Kyoto 27 septembre-1er octobre 2005 (em curso de impressão).

11 Entre os seus mais importantes trabalhos, assinale-se o artigo fundador de JOLIVET, J., "Trois variations médiévales sur l'universel et l'individu: Roscelin, Abélard, Gilbert de la Porrée", in Revue de métaphysique et de morale 1 (1992), pp. 111-55. Reflexões importantes sobre a problemática do nominalismo medieval foram, em particular, os artigos de COURTENAY, W. J., "Nominales and Nominalism in the Twelfth Century", in Jolivet, J., KALuZA, Z. e DE LiBERA, A., (ed.), Lectionum varietates. Hommage à Paul Vignaux, Paris, 1991; e o de NORMORE, C.G., "The tradition of medieval nominalism", in WIPPEL, J.F. (ed.), Studies in Medieval Philosophy, Washington, 1987, pp. 201-17; enfim, o volume Vivarium 30.1 (1992), consagrado ao nominalismo do século XII. Sobre o "complexo de questões-respostas" que configuram a "querela dos universais", veja-se a introdução de A. DE LIBERA, La querelle des universaux, Paris, 1996, pp. 12-28.

12 Sobre as Glosulae, veja-se os mais recentes trabalhos de I. ROSIER-CATACH: para uma apresentação geral do dossier, "The Glosulae in Priscianum and its tradition", in MCLelland, N. and LinN, A. (éd.), Flores grammaticae. Papers in memory of Vivien Law, Münster, 2004, pp. 81-99, e, da mesma autora (a quem agradecemos a generosidade com que nos comunicou este artigo anteriormente à sua publicação), sobre a dimensão semântica da questão dos universais neste comentário, "Les Glo- 
embora deste grande movimento das escolas, Anselmo não deixa por isso de participar das grandes preocupações teóricas da época ${ }^{13}$.

O que resulta, desde já, evidente é que a imbricação destas questões, bem como, frequentemente, a obscuridade dos textos de que dispomos, incita fortemente à prudência no que respeita à apreciação - em termos de 'realismo' ou de 'vocalismo', e, a fortiori de nominalismo - das respostas dadas a duas questões fundamentais da problemática dos universais: a do estatuto ontológico dos predicáveis de Porfírio, por um lado; e a da constituição ontológica do indivíduo, por outro. Pela nossa parte, limitar-nos-emos a analisar aqui alguns dos mais significativos elementos que, na Epistola, se afiguram susceptíveis de contribuir para uma compreensão mais precisa das posições de Anselmo e de Roscelino, no contexto mais amplo do complexo de questões correntemente identificado com a 'querela dos universais'.

A doutrina atribuída a Roscelino de Compiègne, e que Anselmo se prepara para refutar, é eminentemente teológica:

"Se, diz ele, em Deus as três pessoas são uma única coisa (res) - e não três coisas, cada uma por si e separadamente (como três anjos ou três almas), de maneira, no entanto, a que sejam inteiramente a mesma coisa pela vontade e pela potência - então o Pai, o Espírito Santo, incarnou com o Filho"14.

sulae super Priscianum: sémantique et universaux", Actes du Colloque de Pise (juillet 2006): Gli universali, Pisa (em curso de impressão); ainda sob a direcção da mesma autora, Les Glosulae super Priscianum, Guillaume de Champeaux, Abélard: arts du langage et théologie aux confins des XIe-XIIe, les conditions et enjeux d'une mutation, Actes du Colloque international tenu à Paris, 15-17 février 2007, Turnhout (em curso de impressão). Um catálogo dos comentários anónimos aos textos da logica vetus anteriores a meados do século XII foi composto por MARENBON, J., "Medieval latin commentaries and glosses on aristotelian logical texts, before c. 1150 AD" in BURNETT, Ch., Glosses and commentaries on Aristotelian logical texts. The syriac, Arabic and Medieval latin traditions, Londres, 1993, pp. 80-91 - e, do mesmo autor, o "Supplement to the Working Catalogue and Supplementary Bibliography", in MARENBON, J., Aristotelian logic, platonism and the context of early medieval philosophy in the West, Aldershot, 2000, pp. 128-140. O único destes comentários até aqui publicado é o mais antigo comentário contínuo ao Isagoge de Porfírio, dito do Pseudo-Rabano (P3, como é referido no catálogo de Marenbon e nos estudos subsequentes) por IWAKUMA, Y., in Archives d'histoire d'doctrinale et littéraire du Moyen Âge 75 (2008).

13 Para uma contextualização de Anselmo nos debates coevos, ver MARENBon, J., "Anselm and the early medieval Aristotle", in ID. (éd.), Aristotle in Britain during the Middle Ages, Proceedings of the international conference at Cambridge, 8-11 April 1994, S.I.E.P.M., Turnhout, 1996, pp. 1-20 e YwAKUMA, Y., "The realism of Anselm and his contemporaries", in Luscombe, D.E. e Evans, G.R., Anselm. Aosta, Bec and Canterbury, ed. cit., pp. 120-135.

${ }_{14} \mathrm{DIV}, 1,4$ : " $\mathrm{Si}$, inquit, in deo tres personae sunt una tantum res et non sunt tres res unaquaeque per se separatim, sicut tres angeli aut tres animae, ita tamen ut volun- 
Roscelino afirmaria assim, na formulação de Anselmo, que as três pessoas da Trindade são três coisas distintas, per se e separadas. Mais longe, Anselmo discute articuladamente o sentido em que convém entender aqui o termo res ${ }^{15}$ - que, como veremos, nesta formulação, e significando 'pessoa', deverá entender-se como ser singular (pertencendo a uma espécie), ou indivíduo. A segunda recensão apresenta o reforço deliberado da ideia de distinção dessas 'três coisas (res)', pelo acrescento do termo 'separatim'. Esta recensão elimina, no entanto, uma passagem duplamente interessante para nós, figurando na introdução da primeira, e que, não só articula, explicita e assumidamente, a questão trinitária com um dos problemas nevrálgicos das discussões dialécticas da época, como nos testemunha a participação teórica de Anselmo nessas mesmas discussões - ao ponto de, justamente, considerar necessário redigir, e difundir em sua defesa, esta carta-tratado. Trata-se da questão dos parónimos, a que o próprio Anselmo havia, anos antes ${ }^{16}$, consagrado uma obra, o De grammatico. Ora, Roscelino invocaria Anselmo para justificar o paralelo entre a predicação dos nomes das pessoas divinas relativamente a Deus ('Pai', 'Filho', 'Espírito') e a predicação dos parónimos ('branco', 'justo', 'gramático') a respeito do indivíduo:

“... assegurava ter ouvido de mim que, da mesma maneira que se predica Pai, Filho, e, procedendo de ambos, Espírito, se predica 'branco', 'justo', 'gramático' e outros [termos] semelhantes de um homem individual" 17 .

Como o mostrou J. Jolivet num importante estudo, se a questão dos parónimos começou por ser estudada do ponto de vista do seu funcionamento - ou seja, relativamente ao juízo predicativo - isso é particularmente verdade de Anselmo e do De grammatico $^{18}$. A doutrina teológica atribuída a Roscelino assenta portanto, muito claramente, na intersecção da lógica, da gramática, da semântica, e, enfim, da ontologia.

tate et potentia omnino sint idem: ergo pater et spiritus sanctus cum filio est incarnatus".

15 DIV , 2, 12-13.

16 A última datação do De grammatico, proposta por Southern, R., Saint Anselm. Portrait in a Landscape, Cambridge, 1990, antecipa em cerca de vinte anos a datação tradicional, e situa a composição do diálogo entre 1060-1063.

$17 D I V 1,2,282$ : "assereret se a me audisse ita de deo dici patrem et filium et procedentem a patre et filio spiritum, quomodo albus et iustus et grammaticus et similia de quodam individuo homine dicuntur". A refutação deste paralelo pelo argumento da imutabilidade de Deus é feita um pouco adiante, 2, 282-283.

18 JOLIVET, J., "Vues médiévales sur les paronymes", in Revue internationale de philosophie 113/3 (1975), pp. 222-242 - reimp. in ID., Aspects de la pensée médiévale, Paris, 1987, pp. 138-158. 
Esta é a única doutrina explícita e especificamente atribuída por Anselmo a Roscelino. Três outros pontos, em plena coerência com esta doutrina, são principalmente visados pela crítica de Anselmo, sem que, aliás, possamos saber com segurança até que ponto correspondem efectivamente ao ensino de Roscelino. Comecemos por destacá-los da tessitura argumentativa da Epistola. O primeiro deles inscreve Roscelino num movimento mais amplo - o dos novos "heréticos da dialéctica":

“... esses dialécticos do nosso tempo, ou antes, esses heréticos da dialéctica que pensam que as substâncias universais não são mais do que uma emissão de voz, e que não conseguem ver pela inteligência que a cor é distinta do corpo, e a sabedoria de um homem, distinta da sua alma..."19.

Para além de afirmarem que os universais não são mais do que emissões de voz (flatus vocis), estes novos mestres recusariam a distinção entre a cor e o corpo no qual se encontra a cor, entre a alma e a sabedoria que nela se encontra. Dito de outra maneira, recusariam a distinção real entre substância (enquanto substrato) e acidentes (particulares e universais). Ou, nos termos da gramática de Prisciano, entre a qualidade e o sujeito que ela qualifica ${ }^{20}$. Não existem, portanto, acidentes, ou qualidades, independentemente da substância ou do sujeito - não existe 'o branco' ou 'a sabedoria', mas apenas 'o branco deste corpo', ou 'este branco'.

Ora, se os acidentes, ou as qualidades, só existem numa substância ou num sujeito determinados, a consequência lógica será, como veremos já, que existem apenas indivíduos. Tanto mais quanto - é o segundo ponto doutrinal atacado por Anselmo - estes mestres não admitiriam a unidade dos indivíduos ao nível da espécie, com as perigosas implicações teológicas que daí advêm:

"Quem ainda não compreendeu de que modo vários homens são, quanto à espécie, um único homem, como poderá compreender, nessa altíssima e secretíssima natureza, de que maneira várias pessoas - cada uma das quais, tomada à parte, é o Deus perfeito - são um Deus único? Quem tem o espírito tão obscurecido que não consegue discernir o cavalo da sua cor, como poderá distinguir entre um Deus único e as suas várias relações?"21.

${ }_{19} \mathrm{DIV}, 1$, 9: "illi utique nostri temporis dialectici, immo dialecticae haereticii, qui non nisi flatum vocis putant universales esse substantias, et qui colorem non aliud queunt intelligere quam corpus, nec sapientiam hominis aliud quam animam".

20 Segundo Prisciano (cuja caracterização do nome determina a orientação de grande parte das discussões lógico-gramaticais da época), "Proprium nominis est substantiam et qualitatem significare" - Inst. Grammat, ed. Keil, I, 55, 1.6.

21 DIV , 1, 10: "Qui enim nondum intelligit quomodo plures homines in specie sint 
A estrutura onto-lógica subjacente a esta discussão é, obviamente, a dos predicáveis da árvore de Porfírio, que Anselmo tem certamente em mente ao referir a unidade da espécie ${ }^{22}$ - cuja caracterização nestes termos é característica das posições realistas sobre os universais. O terceiro ponto criticável não é mais do que o corolário dos anteriores, já que, se se recusa admitir a existência do homem ao nível da espécie - enquanto unidade de natureza e enquanto universal - então só se reconhece a existência dos indivíduos:

"Em suma, quem não consegue compreender que o homem seja algo mais que o indivíduo, não compreenderá jamais o homem a não ser como pessoa humana. Com efeito, todo o homem individual é pessoa"23.

A solidariedade teórica destas teses é manifesta. Não reconhecendo aos universais outra consistência ontológica que não a de meras emissões de $v_{0 z}{ }^{24}$, estes mestres recusam a existência de uma natureza separada e comum - na árvore de Porfírio, a espécie - aos indivíduos de um mesmo tipo. Da mesma maneira, não admitem a existência, separada e autónoma, dos acidentes e das qualidades, uma vez que não distinguem o acidente da substância em que se encontra, nem a qualidade do sujeito que qualifica. Não reconhecem, em suma, senão a realidade ontológica do particular sensível, ou do indivíduo. Encontramos aqui, por conseguinte, relativamente ao estatuto ontológico dos universais e à constituição ontológica dos indivíduos, duas das teses susceptíveis de caracterizar uma posição, se não nominalista, pelo menos 'vocalista' 25 . No que diz respeito às suas implicações teológicas, é bom de ver que, nos termos em que a questão se coloca na época, uma posição realista no que respeita ao estatuto ontológico destes predicáveis é a que mais facilmente se adequa, não só à reflexão sobre a unidade e trindade divinas, mas igualmente a alguns dos dogmas fundamentais do Cristianismo, como é o caso do pecado original e da sua transmissão, ou, precisamente, da Incarnação de Cristo. Resta

unus homo: qualiter in illa secretissima et altissima natura comprehendet quomodo plures personae, quarum singula quaeque perfectus est deus, sint unus deus? Et cuius mens obscura est diiudicandum inter equum suum et colorem eius: qualiter discernet inter unum deum et plures relationes eius?". Os itálicos são nossos.

22 Cf. sobretudo a célebre passagem, de inspiração neo-platónica, da Isagoge Porphyrii (translatio Boethii), 6.20, ed. L. Minio-PALuELlO, Aristoteles latinus I, 6-7, Bruges-Paris, 1966, p. 12: "participatione enim speciei plures homines unus".

${ }_{23} \mathrm{DIV}, 1,10$ : "Denique qui non potest intelligere aliquid esse hominem nisi individuum, nullatenus intelliget hominem nisi humanam personam. Omnis enim individuus homo est persona".

24 Esta é, igualmente, uma posição característica das Glosulae - cf. RosIER-CATACH, I., "Les Glosulae super Priscianum: sémantique et universaux", p. 5.

25 Cf. Ywakuma, Y., "Vocales...". 
saber até que ponto a refutação de Anselmo das teorias de Roscelino ou, talvez mais exactamente, destes novos mestres - configura uma posição inequivocamente realista.

A refutação de Anselmo parte de uma reformulação da tese de Roscelino: ou se admite que o Pai e o Espírito Santo incarnaram com o Verbo, ou se aceita que existem três deuses, e não um único Deus ${ }^{26}$. A análise da significação do termo res, a que procede Anselmo um pouco adiante, tende, com efeito, a justificar a acusação de triteísmo, uma vez que, aos seus olhos e neste contexto polémico, só pode significar o que há de comum às três pessoas trinitárias ${ }^{27}$. $\mathrm{O}$ erro de Roscelino consiste então em descurar três conceitos fundamentais da teologia trinitária, a saber: os conceitos de natureza, de pessoa e de relação - o que o impede, por conseguinte, de distinguir entre a unidade da natureza e a trindade das Pessoas. Esta distinção permitir-lhe-ia ver na incarnação, não uma união de duas naturezas (divina e humana), mas uma união de pessoas, deixando incólume a natureza, una e trina, de Deus ${ }^{28}$.

De resto, diz Anselmo, a comparação rosceliniana entre a trindade divina e três anjos, ou três almas, mostra bem que não se refere à pluralidade, ou à separação das pessoas, segundo o que lhes é próprio. Com efeito, de dois anjos, ou de duas almas, não dizemos nunca que são uma única coisa, idêntica em número - isto é, distinta e discreta -, ao passo que, de Deus, dizemos que é uno pelo número ${ }^{29}$ e pela natureza. Ou seja, de anjos, ou de almas, falamos (e predicamos) segundo a categoria da substância; das pessoas divinas, segundo a da relação ${ }^{30}$. A questão de fundo é, portanto, a da contraposição entre a trindade das pessoas divinas, por um lado, e a pluralidade dos indivíduos concretos perante a unidade da espécie, por outro ${ }^{31}$. Descurando a diferença ontológica fundamental

26 Cf. DIV, 1, 5.

$27 D I V, 2,12-13$ : com efeito, se o termo res se referisse ao que é próprio a cada uma das pessoas, diz Anselmo, referir-se-ia então a uma trindade de pessoas - o que não somente é aceite, como é postulado pela doutrina católica.

28 DIV , 9, 23-24.

29 Como é corrente nos textos da época (e de acordo com o principio da individuação pelos acidentes figurando no De trinitate, 1 de Boécio) a identidade pelo "número" significa aqui o indivíduo, como unidade discreta e distinta de todos os outros indivíduos da mesma espécie. Dizer de dois anjos que seriam idênticos pelo número seria, assim, um contra-senso.

$30 \mathrm{DIV}, 2,13$ : "Nempe de nulla una et eadem numero de duobus angelis dicitur aut de duabus animabus, sicut patrem aut filium dicimus de deo uno numero et unum numero deum de patre et filio (...) nec credimus nec dicimus plures esse deos, sed ita unum deum esse numero sicut natura, quamvis pater et filius non sint unus, sed duo. Angelum enim et animam secundum substantiam dicimus, non secundum relationem". Os itálicos são nossos.

$31 \mathrm{DIV} 1,5,286$ : "de nulla namque una numero substantia duo angeli predicandur, nec 
entre Deus e o criado, Roscelino recusaria admitir, também em matéria teológica, uma "natureza comum" 32 , independente e separada da pluralidade dos indivíduos em que se particulariza.

Num segundo momento, visando a elucidação da dupla natureza de Cristo e da unidade da sua pessoa (enquanto indivíduo) os fundamentos onto-lógicos e semânticos da posição de Anselmo são mais explícitos. Articulada com a semântica do nome - a que, precisamente, se consagra o De grammatico - encontramos aí a afirmação de duas das principais teses realistas: a da existência da "natureza comum" (rejeitada por Roscelino e pelos novos "heréticos da dialéctica"), já referida e identificada à espécie; e a da individuação pelos acidentes ${ }^{33}$ :

“Com efeito, quando se diz 'homem', significa-se somente a natureza que é comum a todos os homens. Ao invés, quando apontamos, dizendo 'este homem ou aquele', ou [quando utilizamos] o nome próprio, 'Jesus', designamos uma pessoa que tem, juntamente com a natureza [comum], uma colecção de propriedades, pelas quais o homem comum se torna singular e se distingue dos outros singulares. (...) [Relativamente a Jesus] nem o Filho de Deus pode ser designado ou nomeado pessoalmente sem o filho do homem, nem o filho do homem sem o Filho de Deus, porque aquele que é Filho de Deus é o mesmo também que é o filho do homem, e que o conjunto das propriedades do Verbo e do homem assumido é o mesmo. Porque é impossível que a colecção de propriedades de pessoas diversas seja a mesma, ou lhes seja predicada reciprocamente. Com efeito, a colecção de propriedades de Pedro não é a mesma que [a colecção de propriedades] de Paulo, e Pedro não se chama Paulo, nem Paulo, Pedro" ${ }^{\text {34. }}$

ulla una numero substantia dicitur de duobus angelis, sicut deus qui est unus et solus est dicitur de patre et filio...".

32 Cf. n. 35 infra.

33 Tal como a tese da unidade da espécie numa natureza comum, também a da individuação pelos acidentes provém de PORFíRIO, Isagoge, 7.20-7.25, 13-14. Ambas as teses são valorizadas pelo segundo Comentário de Boécio ao Isagoge - no qual Boécio desenvolve aquela que A. de Libera chama "a teoria do sujeito único", de importância decisiva nas primeiras teorias realistas (e, em particular, na primeira teoria de Guilherme de Champeaux, dita "teoria da essência material") - cf. DE LIBERA, A., L'art des généralités, Paris, 1999, pp. 235-249 e BRUMBERG-CHAUMONT, J., "Les universaux dans P3", in ROSIER-CATACH, I. (dir.), Les Glosulae super Priscianum, Guillaume de Champeaux, Abélard (em curso de impressão). Sobre a admissão anselmiana do princípio da individuação pelos acidentes, veja-se ERISMANN, Ch., "Proprietatum collectio. Anselme de Canterbury et le problème de l'individuation", in Medievalia. Textos e estudos 22 (2003), pp. 55-71.

34 DIV , 11, 29: "Nam cum profertur 'homo', natura tantum quae communis omnibus est hominibus significatur. Cum vero demonstrative dicimus 'istum vel illum hominem' vel proprio nomine 'IESUM', personam designamus, quae cum natura 
A "natureza comum"35 é assim significada pelo nome de substância, 'homo'. O indivíduo, por seu lado, para além da natureza comum (espécie), é definido e distincto de todos os outros indivíduos da mesma espécie por uma colecção única de propriedades, e "designado" ou "nomea$d o$ " pelo demonstrativo ou pelo nome próprio ${ }^{36}$. O erro de Roscelino consiste pois em não considerar, em matéria trinitária, senão o que pode ser assim nomeado ou designado, "tal coisa (tale aliquid)", como o são as pessoas humanas:

"E, como vê que um [único] homem não pode ser várias pessoas, nega a mesma coisa de Deus" 37 .

Compreende-se assim a acusação de Anselmo que, na primeira recensão da Epistola, acusa Roscelino e os seus pares de terem uma razão obnubilada pelas "imagens corporais". Incapazes de se elevar à intelecção das $\operatorname{coisas}^{38}$, não reconheceriam senão os particulares sensíveis ${ }^{39}$.

collectionem habet proprietatum, quibus homo communis fit singulus et ab aliis singulis distinguitur. (...) Neque enim personaliter filius dei designari potest vel nominari sine filio hominis, et eadem est verbi et assumpti hominis proprietatum collectio. Diversarum nim personarum impossibile est eandem esse proprietatum collectionem, aut de invicem eas predicari. Nam PETRI et PAULI non est eadem proprietatum collectio, et PeTRUS non dicitur PAUlus, nec PAUlus Petrus".

35 A identificação dos universais com "naturae" é corrente no segundo Comentário de Boécio à Isagoge de Porfírio (cf. por ex., ed. Schepps-Brandt, CSEL, XLVIII, Vienne, 1906, p. 165, 12-14), e amplamente aceite pelos autores desta época (por exemplo, em Odon de Cambrai, que sustenta como Anselmo o princípio da individuação pelos acidentes).

36 Cf. também um pouco mais adiante, DIV, 11, 29 (itálicos nossos): "Cum ergo 'verbum caro factum est', naturam assumpsit, quae sola hominis nomine significatur et semper est alia a natura divina, non aliam assumpsit personam, quoniam eandem habet cum assumpto homine proprietatum collectionem. Non enim idem est homo et assumptus a verbo homo, id est IESUS; quoniam in nomine hominis, sicut dictum est, sola intelligitur natura, in assumpto vero homine vel in nomine IESU intelligitur cum natura, id est cum homine, collectio proprietatum, quae est eadem eidem assumpto homini et verbo".

37 DIV , 12, 30: "Nam nec deum nec personas eius cogitat, sed tale aliquid, quales sunt plures humanae personae. Et quia videt unum hominem plures personas esse non potest, negat hoc ipsum de deo. Non enim idcirco dicuntur tres personae, quia sint tres res separatae sicut tres homines, sed quia similitudinem habent quandam cum tribus separatis personis".

38 Como justamente o nota Jolivet, "Trois variations", p. 124, as faculdades mencionados por Anselmo, nesta passagem, são as de Consolatio philosophiae, 5, 27 (ed. C. Moreschini, Munique e Leipzig, 2005, p. 149). Sobre a teoria da abstracção nesta passagem da Consolatio no contexto da teoria do sujeito único de Boécio, cf. DE LIBERA, L'art des généralités, pp. 244-249.

$39 D I V 1,4,285$ : "In eorum quippe animabus ratio, quae et princeps et iudex debet omnium esse quae sunt in homine, sic est in imaginationibus corporeis obvoluta, ut 
Ora, a espécie e o indivíduo são dois dos três significata que, na breve análise da significação dos nomes de substância conduzida no $D e$ grammatico (consagrado quase exclusivamente aos parónimos), pertencem à significação ut unum. Sem entrar no exame da complexa teoria semântica aí discutida ${ }^{40}$, e menos ainda na viva controvérsia sobre o tipo de realismo de Anselmo, que, in fine, aí encontraríamos implícito ${ }^{41}$, vejamos rapidamente alguns elementos dessa obra susceptíveis de contribuir para um melhor entendimento da oposição entre Anselmo e Roscelino.

Como já vimos, a questão sobre que se opõem Roscelino e Anselmo é a da predicação dos nomes das Pessoas divinas - num contexto em que a reflexão sobre a predicação dos termos concretos é então dominada pela questão da paronímia. É ao ensino de Anselmo sobre os parónimos que, como também referimos, Roscelino se refere para justificar a sua posição quanto à predicação dos nomes das Pessoas da Trindade.

Ora, desde a Antiguidade e passando por Boécio, a paronímia é a porta de entrada desse "platonismo de contrabando" já implícito nas $\mathrm{Ca}$ tegorias de Aristóteles ${ }^{42}$. Como o mostrou J. Jolivet num artigo fundador, se a caracterização dos parónimos se apresenta, a partir de finais do século XI, como o ponto de confluência da gramática, da semântica e da ontologia, é porque eles são estudados à luz do confronto entre as Categorias, por um lado, e as Institutiones grammaticae de Prisciano, por outro ${ }^{43}$.

ex eis se non possit evolvere nec ab ipsis ea quae ipsa sola et pura contemplari debet, veleat discernere".

40 A obra de referência para o diálogo de Anselmo é ainda a de D.P. HENRY, The logic of Saint Anselm, Oxford, 1967 e, do mesmo, Commentary on 'De grammatico': the historical-logical dimensions of a dialogue of St. Anselm's, Dordrecht-Boston, 1974. Para uma perspectiva mais geral e actualizada, veja-se KING, P., "Anselm's philosophy of language", in DAVIS, B. et Leftow, B. (éd.), The Cambridge Companion to Anselm, ed. cit., pp. 84-110.

41 Sublinhando o aristotelismo de Anselmo, em particular no De grammatico, a interpretação de Henry tendia a atenuar consideravelmente o realismo das suas posições. Mais recentemente, a sua leitura tem feito objecto de várias críticas, entre as quais cumpre referir a de ADAMS, M.M., "Re-reading 'De grammatico' or Anselm's Introduction to Aristotle's 'Categories'”, in Documenti e studi sulla tradizione filosofica medievale 11 (2000), pp. 83-112 e EAD., "Was Anselme a realist? The Monologium", in Franciscan Studies 32 (1972), pp. 5-14; igualmente críticos de Henry, cf. MARENBON, "Some semantic problems in Anselm's De grammatico", in Heren, M.W., McDonough, C.J. and Arthur, R.G. (éd.), Latin culture in the eleventh century, II, Turnhout, 2002, pp. 73-86 e, mais recentemente, retomando as críticas de Adams, Boschung, P., From a topical point of view. dialectic in Anselm of Canterbury's 'De Grammatico', Leiden-Boston, 2006.

42 Cf. DE LIBERA, A., La querelle des universaux, espec. pp. 59-63.

43 Jolivet, J., "Vues médiévales sur les paronymes", pp. 222-242; e também, do mesmo autor, "Quelques cas de 'platonisme grammatical' du VIIe au XIIe siècle", 
Considerado gramaticalmente como um nome derivado, o parónimo (a que chamamos hoje 'adjectivo') deverá significar, de acordo com Prisciano, "uma substância e uma qualidade"44. Mas, nas Categorias (1a10-15), ele figura ao lado do homónimo e do sinónimo, enquanto elemento de uma tripartição de coisas. Marciano Capela e Boécio acentuarão ainda a dimensão ontológica, o primeiro pela associação das qualidades a essências ideais, o segundo pela extensão do conceito de participação até à esfera do léxico ${ }^{45}$. Por outro lado, se a tradição lógica segue, como Boécio, Categorias 2b28, em que grammaticus é dado como exemplo de qualidade, a tradição gramatical afirma, com Prisciano, que grammaticus é um nome de substância ${ }^{46}$. A oposição entre 'realistas' e 'vocalistas' funda-se portanto, desde logo, numa tomada de posição exegética relativamente àquela que terá sido a intenção de Aristóteles nas Categorias: a de tratar de coisas, ou a de tratar de palavras. Por seu lado, Anselmo adopta a leitura moderada (e ambígua) de Boécio, segundo a qual Aristóteles trata de palavras que significam coisas $^{47}$ - à luz da qual o De grammatico visa responder à questão de saber se um parónimo, como grammaticus, é uma substância ou uma qualidade. Registe-se entretanto, com J. Marenbon, que a posição de Anselmo é a que adoptam a maior parte dos primeiros comentários aos principais textos da logica vetus - geralmente associados ao realismo ${ }^{48}$.

A resposta de Anselmo parte de uma distinção, decisiva, entre significação (própria, ou per se) e apelação - ou, em termos contemporâneos,

in Gallais, P., et Riou, Y.-J. (ed.), Mélanges offerts à René Crozet (à l'occasion de son soixante-dixième anniversaire), Poitiers, suppl. aux Cahiers de Civilisation Médiévale, vol. i, 1966, pp. 93-99 (ambos reimp. in ID., Aspects de la pensée médiévale, ed. cit., respectivamente pp. 138-158 e 71-77).

44 Cf. supra n. 20.

45 JOLIVET, J., "Vues médiévales...”, pp. 224-225.

46 Prisciano, Institutiones, 1, II, 25, p. 58.24, e secção 24, p. 58.17.

47 BoÉCIO, In Categorias, P.L., 159C: "in eo quod significantes sunt"; cf. De grammatico, 17, 162: "Non enim intendebat ostendere quid sint singulae res, nec quarum rerum sint appellativae singulae voces: sed quarum significativae sint. Sed quoniam voces non significant nisi res: dicendo quid sit quod voces significant, necesse fuit dire quid sint res".

48 É designadamente o caso de dois importantes comentários, às Categorias e à Isagoge de Porfírio - respectivamente C8 e P14 - que Y. Iwakuma considera estreitamente associados ao círculo de Guilherme de Champeaux: veja-se YWAKUMA, Y., "William of Champeaux on Aristotle's Categories", in BIARD, J. et Rosier-CATACH, I. (ed.), La tradition médiévale des Catégories (XIIe-XVe siècles), Actes du XIIIe Symposium européen de logique et sémantique médiévales (Avignon, 6-10 juin 2000), Louvain-la-Neuve-Paris, 2003, pp. 313-328, bem como a introdução à sua edição de P3 (cf. supra n.13); cf. MARENBON, J., "Anselm and the early medieval Aristotle", pp. 4-9, com passagens relevantes destes textos. 
entre sentido e referência ${ }^{49}$. Assim, e do ponto de vista do juízo predicativo, grammaticus significa 'gramática' (qualidade), mas não pode funcionar como atributo daquilo que significa; em contrapartida, pode ser atribuído ao homem (substância), sem o significar ${ }^{50}$. Em suma, na concisa formulação de J. Jolivet, "ele significa aquilo de que não é apelativo, é apelativo daquilo que não significa" ${ }^{1}$. Uma segunda distinção, interna à significação, supõe, precisamente, a distinção que Roscelino se recusaria admitir entre substância e qualidade: trata-se da significação per se, ou essencial (substantialis), e da significação per aliud, acidental (accidentalis) ${ }^{52}$. Albus significa assim per se a qualidade, e, per aliud, a substância qualificada (particular sensível) ${ }^{53}$. Por último, a distinção entre a significação de algo $u t$ unum - enquanto unidade - e a que não o é, diz principalmente respeito aos termos de substância. Os exemplos dados por Anselmo de significata ut unum são justamente o género, a espécie, o indivíduo - cuja constituição resulta, como na Epistola, da associação da espécie a uma colecção de acidentes. Um termo de substância como 'homem' significa por conseguinte o género e a diferença - ou seja, a espécie - ut unum ${ }^{54}$.

49 Cf. De grammatico, XII, 156-157 - onde, sobre a appellatio, nos diz Anselmo: "Appellativum autem nomen cuiuslibet rei nunc dico, quo res ipsa usu loquendi appellatur". Registe-se, entretanto, que a distinção entre significatio e nominatio (ou, mais precisamente, entre 'significação por representação' e 'significação por imposição') figura já nas Glosulae in Priscianum, para quem o nome não significa "substância e qualidade", mas nomeia a substância e significa a qualidade - cf. MARENBON, J., "Anselm and the early medieval Aristotle", p. 8, n.19 (com excerto do texto), e I. Rosier-CATACH, "The Glosulae in Priscianum and its tradition", p. 10. MEWS, C., "St. Anselm and the Development of Philosophical Theology in Twelfth Century Paris", in Gasper, G. e Kohlenberger, H., (éd.), Anselm and Abelard. Investigations and Juxtapositions, Toronto, PIMS, 2006, pp. 196-222, coloca em evidência certos indícios - a nossos olhos, não conclusivos - de que Anselmo conheceria as Glosulae.

50 Cf. De grammatico, 12,157.

51 Jolivet, J., "Vues médiévales...", p. 226. Ou seja, nas palavras do mesmo autor, p. 241: "On ne peut certes faire du nom blancheur le prédicat du nom d'une substance, alors qu'il peut être sujet dans une proposition: cela incite à sentir la blancheur comme quelque chose d'existant en soi".

52 Cf. De grammatico, 17, 163.

53 Trata-se do célebre exemplo do cavalo branco numa casa: cf. De grammatico, 14, 159-161 - espec. 160-161: "Nempe nomen equi etiam priusquam sciam ipsum equum album esse, significat mihi equi substantiam per se, et non per aliud. Nomen vero albi equi substantiam significat non per se, sed per aliud, id est per hoc quia scio equum esse album. (...) Sed quoniam scio albedinem esse in equo, et hoc per aliud quam per nomen albi, velut per visum: intellecta albedine per hoc nomen, intelligo equum per hoc quod albedinem scio esse in equo, id est per aliud quam per nomen albi, quo tamen equus appellatur". Recorde-se, de passagem, que, nos termos de Anselmo, Roscelino não distinguia entre "o cavalo e a sua cor".

54 De grammatico, 20, 166: "Unum non fit ex pluribus nisi aut compositione partium 
Ora, como o observa M. M. Adams (cuja interpretação do De grammatico nos parece a mais consistente e argumentada) segundo a doutrina das Categorias, tal como a interpreta Anselmo, esse unum assim constituído é substância, e não qualidade ${ }^{55}$. Em contrapartida, e ainda de acordo com as Categorias, os parónimos ('albus', 'grammaticus') não significam a substância e a qualidade ut unum, uma vez que tanto a gramática como a brancura são acidentes, e não differentiae da substância ${ }^{56}$. A distinção semântica já operada entre a qualidade e a substância pelo par significação per se / significação per aliud é assim acentuada no contraste com a significação ut unum. No que diz respeito à querela dos universais, o problema é, segundo esta eminente especialista de Anselmo, que, na curta discussão do De grammatico sobre a semântica dos nomes abstractos, Anselmo não nos diz que os nomes abstractos, tais como 'gramática', ou 'brancura', nomeiam o que quer que seja. Em contrapartida, os termos de substância, como 'homem', são principalmente significativos e apelativos de substância, enquanto unidade ${ }^{57}$ - pelo que 'homem' seria, ao mesmo tempo, apelativo da espécie (e não do indivíduo), sendo essa apelação de espécie uma significação per se. A Epistola parece justamente confirmar esta interpretação, pela afirmação, que vimos acima, segundo a qual, no nome 'homem', apenas se compreende a natureza, ou seja, que 'homem' significa a natureza comum a todos os homens, ou seja, a espécie. Por seu turno, os nomes próprios, bem como os nomes comuns acompanhados de demonstrativos ou de deíficos ('este homem') compreendem, e portanto designam, uma pessoa, incluindo a natureza comum e a colecção de propriedades pela qual se distingue dos outros. Esses termos singulares parecem, por conseguinte, nomear os indivíduos per $s e^{58}$.

Objecto de viva controvérsia entre os especialistas, a questão do realismo de Anselmo - que nos limitamos simplesmente a enunciar aqui emerge, por conseguinte, do exame dos significata per se e ut unum, mais

quae sunt eiusdem praedicamenti, ut animal constat corpore et anima; aut convenientia generis et differentiae unius vel plurium, ut corpus et homo; aut specie et proprietatum collectione, ut Plato".

55 Cf. M. M. ADAMS, "Re-reading 'De grammatico"”, p. 87.

56 De grammatico, XIII, 157-159.

57 Como o sublinha J. Marenbon, se Anselmo distingue entre o que significa o nome de uma coisa, por um lado, e toda a variedade de características que essa coisa deve ter (cor, racionalidade ou irracionalidade, no exemplo de 'animal'), por outro ele não admite, no entanto, que os nomes de substância possam significar separadamente as qualidades que pertencem à sua definição: eles significam-nos ut unum com a substância - cf. MARENBON, J., "Anselm and the early medieval Aristotle", p. 9.

58 Cf. ADAMS, M. M., “Re-reading 'De grammatico'”, pp. 87-89. 
precisamente do estatuto ontológico que convém atribuir, respectivamente, à qualidade e aos predicáveis que são o género, a espécie e o indivíduo. M. M. Adams sublinha justamente o quanto é fácil passar do comentário de voce, segundo o qual grammaticus é apelativo dos homens que possuem a gramática, à afirmação de re, segundo a qual 'grammaticus' é um homem, e, portanto, uma substância; ou seja, se a leitura in voce diz que 'grammaticus', per se, significa a gramática, e portanto, per se, é uma qualidade, a leitura de re diz que 'grammaticus' é uma qualidade 59 .

$\mathrm{Na}$ interpretação, já clássica, de D. P. Henry, Anselmo escapa ao "realismo cru" de duas maneiras: do ponto de vista semântico, pela rejeição da caracterização do nome de Prisciano, que conduziria à indistinção entre os nomes significando a substância e os nomes significando a qualidade - e, dessa maneira, à primeira tese característica do "realismo cru", segundo a qual os termos gerais como 'homem' significam da mesma maneira que os nomes próprios e nomeiam entidades separadas e existentes; do ponto de vista lógico e ontológico, e relativamente aos parónimos, pela equação entre significação per se e per aliud, por um lado, e sentido e referência, por outro, correspondendo a um duplo nível do verbo substantivo (esse) no juízo predicativo - que Henry veria, não já no $D e$ grammatico, mas no Monologion ${ }^{60}$. Ora, as críticas de M. M. Adams a esta interpretação têm vindo a impor-se, e, com elas, os seus argumentos, contrários a Henry, de que, como os termos próprios de substância (como 'Platão'), também os termos comuns de substância (como 'homem'), podem nomear o que significam per se. No mesmo sentido, a contraposição do De grammatico entre lógicos e gramáticos não exprimiria, segundo M. M. Adams, uma recusa da caracterização do nome de Prisciano, mas, simplesmente, a introdução de nuances exigidas pela ênfase na função significativa per se, em detrimento da função apelativa (que depende do contexto $)^{61}$.

Em todo o caso, o que nos parece evidente é que, mesmo admitindo que a questão da referência se apresentava a Anselmo nos termos em que hoje a colocamos, a crítica interna do De grammatico, e a distinção entre significatio e appellatio de que parte, não permitem, por si só, uma resposta cabal e inequívoca ao problema do estatuto ontológico dos principais significata (género, espécie, indivíduo e qualidade). Por outro lado, e mesmo eliminando qualquer possibilidade de evolução doutrinal entre a

59 Cf. ADAMS, M. M., "Re-reading 'De grammatico"”, p. 88.

60 Cf. Henry, D. P., The logic of St. Anselm, esp. pp. 96-107.

${ }^{61}$ Cf. ADAMS, M. M., "Re-reading 'De grammatico"”, pp. 97-105; ver iguamente EAD., "Was Anselm a realist?", pp. 5-14, onde, através de um exame da ontologia do Monologion, argumenta contra a hipótese de Henry do duplo nível de esse, e MARENBON, J., "Some semantic problems...". 
composição do Monologion e a do De grammatico e da Epistola, o recurso interpretativo à ontologia e à semântica da primeira obra de Anselmo não se afigura susceptível, no estado actual da investigação, de fornecer respostas inequívocas a este problema.

Assim, é por caminhos muito diferentes que M. M. Adams e Y. Iwakuma, por exemplo, chegam ambos à afirmação de uma certa forma de realismo de Anselmo. Enquanto a primeira (no contexto da sua crítica a Henry) invoca o 'platonismo' do Monologion ${ }^{62}$, Iwakuma sublinha a fidelidade destes autores a Aristóteles e a Boécio (designadamente, ao Boécio do segundo Comentário à Isagoge) e postula, por seu turno, a necessidade de dissociar 'platonismo' e 'realismo'. Frequentemente classificadas como platónicas, as teorias realistas de Anselmo, de Odon de Cambrai ou ainda de Guilherme de Champeaux são na realidade, para este eminente especialista, "estádios do realismo "aristotélico"”63.

Com efeito, o que mostra o estudo destes primeiros comentários aos textos da logica vetus (ou às Institutiones de Prisciano) é que as numerosas nuances das diversas posições realistas - tais como são expostas pelas críticas de Abelardo ou apresentadas nestes comentários - podem ser perfeitamente compreendidas no âmbito da tradição aristotélico-boeciana, de que se reivindica, aliás, a maior parte destes autores ${ }^{64}$. Por outro lado, e anteriormente à crítica abelardiana, teses que consideramos 'realistas' e teses 'vocalistas' parecem co-habitar pacificamente nestes textos. Assim, como o sublinha o seu editor, o mais antigo comentário ao Isagoge de Porfírio, P3, não vê nenhuma contradição entre as duas principais teses que avança, relativas aos indivíduos e aos universais: a primeira, que recusa a existência aos universais e afirma que só existem verdadeiramente (essentialiter) os indivíduos; a segunda, que as mesmas coisas são individuais e universais - sendo que estes, entendidos como natureza comum, não existem nunca separadamente dos indivíduos. Justamente, para Iwakuma, as importantes passagens do Monologion 30 e 27 exprimiriam posições muito próximas destas teses, mostrando, em suma, que Anselmo não admitiria a existência separada de coisas universais, mas somente de indivíduos, considerados segundo a essência universal (ou natureza comum) que partilham com outros indivíduos da mesma espé-

62 ADAMs, M.M., "Was Anselm a realist?”, p. 13; as passagens referidas por M.M. Adams são Monologion 9-12 e 29-36.

63 YwaKUMA, Y., "The realism of Anselm”, p. 132; e, p. 125: “Anselm would never have considered himself to be a platonist in any sense in developing his universals theory".

64 IWAKUMA, Y., "The realism...”, espec. pp. 132-135. Para um exame aprofundado das teorias realistas até ao século XII, a partir das críticas de Abelardo, veja-se DE LiBERA, A., L'art des généralités, espec. pp. 305-367. 
cie. Mais ainda, esta primeira obra de Anselmo estaria na origem da primeira teoria - realista - de Guilherme de Champeaux sobre os universais, ou "teoria da essência material", criticada por Abelardo na sua Logica ingredientibus ${ }^{65}$.

Como quer que seja, e para regressar a Roscelino e às críticas de Anselmo na Epistola, o que resulta óbvio é que, se a análise do nome conduzida por Anselmo se inscreve nos limites de uma reflexão sobre as diferentes maneiras de significação, a de Roscelino parece, ela, centrar-se sobre a referência. Partindo da aplicação estrita da caracterização do nome de Prisciano, Roscelino insiste, na Epistola ad Abaelardum, que o nome do Pai não pode ser identificado com o nome do Filho ou o do Espírito, cada nome próprio correspondendo à sua própria coisa (res), efectivamente existente. Como todos os outros nomes, cada nome divino significa uma substância; a diferença é que, em Deus, o nome significa apenas a substância, sem qualquer qualidade. No mesmo sentido, não é possível admitir partes em Deus, das quais uma seria a substância, outras as Pessoas - não podemos falar de Deus como falamos de um todo composto de partes, como por exemplo de um homem, composto pelo corpo e pela alma. 'Pessoa' e 'substância' significam por conseguinte a mesma coisa de resto, como Roscelino não deixa de sublinhar, os Gregos falam, não de três pessoas, mas de três substâncias ${ }^{66}$.

Deixando aqui de lado o alcance teológico desta posição ${ }^{67}$, interessa-nos observar que, para Roscelino, a relação entre a substância e o nome é primária - ou, dito de outra maneira, que a função do nome é de referir. Esse referente é para Roscelino, sempre, uma substância qualificada um particular sensível, ou um indivíduo, que vemos distintos uns dos outros e que são as únicas coisas a que podemos atribuir a existência. Um termo de substância como 'homem' não significa qualquer "natureza

65 ABELARDo, Logica ingredientibus, ed. Geyer, p. 10, 17-29.

66 RosCELINO, Epistola ad Abaelardum, ed. Reiners, pp. 29-74 - as passagens mais relevantes são dadas por MEWS, "The trinitarian doctrine", pp. 354-358.

67 Segundo Mews, “The trinitarian doctrine”, p. 356, Roscelino admite efectivamente ter afirmado a substância singular da trindade divina, como o acusa Abelardo, não no sentido do Sabelianismo, mas no sentido em que a substância divina possui uma tal unidade que nenhuma outra pluralidade de coisas pode ter: "Roscelin was insisting on the distinct reference of nouns applied to God, namely pater, filius and spiritus sanctus. (...) to assert that the three persons constituted a single thing was to confuse the three persons. Anyone who wanted the three names to signify a single thing necessarily argued that the Father became incarnate because he was also the Son. This plurality was proclaimed by the Greek Church". Registe-se, entretanto, que, na interpretação de Mews, Roscelino não estava, nesta resposta a Abelardo, a negar a existência dos universais, mas, simplesmente, a examiná-los enquanto entidades linguísticas - ibidem, p. 364. 
comum" ou "espécie", cuja existência separada e abstracta ele recusa, mas designa uma substância, um indivíduo humano. Sem esta referência, concreta e singular, nomes abstractos (de qualidades, como 'brancura', ou de substância, como 'animal' ou 'homem') são conceitos vazios do ponto de vista da existência: são flatus vocis. Como o mostra J. Jolivet, nesta semântica da referência, é a função apelativa que será privilegiada em detrimento da significação, das relações de paronímia ou das possibilidades de inferência segundo os significados, sem que sobre lugar para a translatio ou para outra função significativa que não seja a da imposição dos nomes ${ }^{68}$.

Não é absolutamente nossa intenção proceder aqui a uma tentativa aventurosa de reconstituição da leitura que terá feito Roscelino da doutrina anselmiana dos parónimos - supondo que aquela a que Roscelino se refere seja a mesma que encontramos no De grammatico. De tudo o que temos vindo a ver, o que nos parece possível poder dizer é que, ignorando as distinções semânticas de Anselmo, Roscelino consideraria que a significação dos parónimos e a significação dos nomes de substância se faz da mesma maneira - e que, por conseguinte, a predicação de ambos se faria igualmente da mesma maneira. Ora, como vimos, no De grammatico os nomes de substância significam ut unum, ou seja, significam a substância com as suas qualidades enquanto unidade. Ao invés, os parónimos significam, de duas maneiras diferentes, per se (a qualidade, ou o termo abstracto de qualidade) e/ou per aliud (a ocorrência, ou a qualidade num substrato). De acordo com o particularismo ontológico que defende, Roscelino ter-se-ia limitado a admitir apenas a significação per aliud (da substância qualificada), recoberta pela significação ut unum do indivíduo, concebido como um todo concreto. Ou seja, os únicos modos de significação que exprimem a existência real das coisas.

\section{RESUMO}

Anselmo foi, como o seria um pouco mais tarde Abelardo, um dos mais eminentes adversários de Roscelino de Compiègne, considerado geralmente como o iniciador da posição dita vocalista no que diz respeito ao estatuto ontológico dos termos universais. É sobretudo no De incarnatione verbi que Anselmo desenvolve os seus argumentos contra as implicações teológicas e trinitárias das doutrinas de Roscelino, «herético da dialéctica», que defende que «as substâncias

68 JoLIVET, J., "Trois variations", pp. 125-127. Sobre a importância da paronímia na problemática da translatio, veja-se, em primeiro lugar, DE LIBERA, A., "Boèce et l'interprétation médiévale des Catégories. De la paronymie à la denominatio", in Motte e Denooz, J. (ed.), Aristotelica secunda. Mélanges offerts à Christian Rutten, Université de Liège, CIPL, 1996, pp. 255-264. 
universais são simples palavras» (flatus vocis). Distante embora dos termos em que, desde o final do século XI, se configura a chamada «querela dos universais» (tributária do corpus da logica vetus, e designadamente das Categorias e do Peri hermeneias de Aristóteles, a que se juntam as Institutiones de Prisciano), a crítica de Anselmo a Roscelino, em si mesma e nos seus pressupostos, incide no entanto sobre alguns dos aspectos, dialécticos e semânticos, a que o debate nas escolas dará maior relevo. A essa luz, analisaremos aqui a crítica anselmiana à posição de Roscelino - que não distingue «o cavalo da sua cor», e que «não compreende como vários homens são um único homem na espécie» -, em particular no que diz respeito à relação entre substância e acidente (ou qualidade, segundo a gramática de Prisciano) e à semântica do nome.

\section{RÉSUMÉ}

Avec Abélard, Anselme fut le plus éminent critique de Roscelin de Compiègne, représentant majeur de la position dite 'vocaliste' concernant le statut ontologique des termes universaux. L'Epistola de incarnatione Verbi est toute consacrée à la réfutation des doctrines de Roscelin, «hérétique de la dialéctique» qui soutient que «les substances universelles ne sont que des simples mots» (flatus vocis). En eux-mêmes et dans ses présupposés, les arguments d'Anselme portent sur plusieurs des sujets qui nourrissent alors les débats des écoles. Nous nous proposons d'analyser ici la critique anselmienne aux thèses de Roscelin - qui «ne distingue pas entre le cheval et sa couleur», et «ne comprend pas comment plusieurs hommes sont un seul dans l'espèce» - en ce qui concerne surtout la sémantique du nom et le rapport entre substance et accident. 